\title{
Transverse Plane
}

National Cancer Institute

\section{Source}

National Cancer Institute. Transverse Plane. NCI Thesaurus. Code C73849.

A horizontal surface or plane perpendicular to a vertical axis. 